\title{
Pulmonary arterial hypertension associated with chronic hemolytic anemia
}

INSERM

\section{Source}

INSERM. (1999). Orphanet: an online rare disease and orphan drug data base. Pulmonary arterial hypertension associated with chronic hemolytic anemia. ORPHA:275828

Pulmonary arterial hypertension associated with chronic hemolytic anemia (PAH-CHA) is a form of PAH (see this term) characterized by an elevated pulmonary arterial resistance leading to right heart failure observed as a complication of chronic hemolytic anemia. 